\title{
O CASO FAZENDA BRASIL VERDE E O CUMPRIMENTO DA DECISÃO DA CORTE INTERAMERICANA DE DIREITOS HUMANOS
}

\author{
THE CASE OF BRASIL VERDE FARM AND THE COMPLIANCE WITH THE \\ DECISION OF THE INTERAMERICAN COURT OF HUMAN RIGHTS
}

Recebido: 14.10 .2019

Aprovado: 25.03.2020

\author{
Saulo José Casali Bahia \\ Doutor em Direito pela PUC-SP. Professor na \\ UFBA. Juiz Federal. \\ E-MAIL: saulo.bahia@trf1.jus.br. \\ LATTES: \\ http://lattes.cnpq.br/7398414546353246 \\ ORCID: https://orcid.org/0000-0002-3768-3664 .
}

\begin{abstract}
RESUMO: O artigo investiga o cumprimento pelo Estado brasileiro da decisão produzida pela Corte Interamericana de Direitos Humanos (CorteIDH) no caso da Fazenda Brasil Verde, julgado em 20 de outubro de 2016. A CorteIDH estabeleceu que o não reconhecimento, no ordenamento interno brasileiro, do trabalho escravo enquanto crime imprescritível constituía um obstáculo relevante para a garantia da proteção judicial, seguindo o seu entendimento jurisprudencial de que graves violações de direitos humanos não prescrevem na esfera internacional. No cumprimento da decisão, no ano de 2018, ocorreu impetração de Habeas Corpus junto ao TRF da $1^{\text {a }}$ Região, e o artigo analisa o acórdão produzido, que afastou as alegações de incompetência da CorteIDH e de violação ao contraditório, ampla defesa e presunção de inocência, além da prescrição que se pretendia ver reconhecida. Metodologicamente, o estudo de caso, assim, é utilizado para a realização das inferências que podem ser vislumbradas sobre o problema.
\end{abstract}

PALAVRAS-CHAVE: Corte Interamericana de Direitos Humanos; Trabalho escravo; Competência; Habeas Corpus; Imprescritibilidade.

\begin{abstract}
The article investigates the fulfillment by the Brazilian State of the decision produced by the Interamerican Court of Human Rights in the case of "Brasil Verde" Farm (October 20, 2016). The I/ ACourtHR established that the non-recognition, in the Brazilian internal system, of slave labour as a crime not submitted regarding of statutory limitations constituted a relevant obstacle to the guarantee of judicial protection, following its jurisprudential understanding that serious violations of human rights do not prescribe in the international sphere. In compliance with the decision, in 2018, Habeas Corpus was filed with the TRF of the 1st Region, and the article analyzes the judgment produced, which dismissed the allegations of incompetence by the I/ACourtHR and violation of the contradictory, full defense and presumption of innocence, in addition to the statutory limitation that was intended to be recognized. Methodologically, the case study, therefore, is used to make inferences that can be glimpsed about the problem.
\end{abstract}

KEYWORDS: Interamerican Court of Human Rights; Slave Labour; Competence; Habeas Corpus; Statutory limitations. 
SUMÁRIO: 1 Introdução $2 \mathrm{O}$ Caso da Fazenda Brasil Verde (CorteIDH), o cumprimento da decisão no Brasil e a reação interna a este cumprimento 3 Incompetência da CorteIDH para o julgamento do caso 4 Violação ao contraditório, à ampla defesa e à presunção de inocência 5 A inadmissibilidade da prescrição da ação penal em violações graves aos direitos humanos 6 O Habeas Corpus Criminal $n$. 1023279-03.2018.4.01.0000 e o cumprimento da ordem emitida pela CorteIDH 7 Conclusão 8 Referências

\section{Introdução}

Sobre o tema da proibição da escravidão, notabilizou-se o caso da Fazenda Brasil Verde, julgado em 20 de outubro de 2016, quando a Corte Interamericana de Direitos Humanos ("Corte" ou "CortelDH") ordenou que o Estado brasileiro reabrisse investigação para averiguar fatos ocorridos no ano de 2000 na Fazenda Brasil Verde ("Fazenda").

O presente artigo investiga o cumprimento pelo Estado brasileiro da decisão produzida pela Corte, que estabeleceu que o não reconhecimento, no ordenamento interno brasileiro, do trabalho escravo enquanto crime imprescritível constituía um obstáculo relevante para a garantia da proteção judicial, seguindo o seu entendimento jurisprudencial de que graves violações de direitos humanos não prescrevem na esfera internacional.

No cumprimento da decisão, no ano de 2018, ocorreu impetração de Habeas Corpus junto ao TRF da $1^{\text {a }}$ Região, e o artigo analisa o acórdão produzido, que afastou as alegações de incompetência da CorteIDH e de violação ao contraditório, ampla defesa e presunção de inocência, além da prescrição que se pretendia ver reconhecida.

Trata-se, assim, de um estudo de caso, enquanto método de estudo qualitativo e aplicado, no qual se explora um sistema delimitado contemporâneo da vida real (um caso), recolhendo os dados respectivos, desde que possa ser representativo de um conjunto de casos análogos, e guarde significado e importância, autorizando inferências futuras ${ }^{1}$.

\section{Caso da Fazenda Brasil Verde (CortelDH), o cumprimento da decisão no Brasil e a reação interna a este cumprimento}

A Corte Interamericana de Direitos Humanos, em decisão de 20 de outubro de 2016 (publicada em dezembro do mesmo ano) considerou a demanda ajuizada pela Comissão Interamericana de Direitos Humanos (Caso Trabalhadores da Fazenda Brasil Verde contra a República Federativa do Brasil, aberto a partir de uma fiscalização realizada na Fazenda Brasil Verde pelo Ministério do Trabalho, em companhia de agentes da Polícia Federal, em 15 de março de 2000) parcialmente procedente para declarar o Estado brasileiro responsável por: i) violação do dever de diligência em atos constitutivos de escravidão, servidão ou tráfico de pessoas, com o fim de evitar a perpetuação de situação de impunidade (art. 6.1 c/c 1.1, 3, 5, 7, 11 e 22 da Convenção); ii) violação da garantia judicial ao prazo razoável (art. 8.1 c/c 1.1 Convenção); iii) violação do direito à proteção judicial, diante da ausência de instrumentos idôneos e efetivos de investigação e responsabilização (art. 25 da Convenção); e iv) violação ao direito à personalidade jurídica,

1 Sobre a metodologia de estudo de caso, ver: CRESWELL, John W. Investigação qualitativa e projeto de pesquisa: escolhendo entre abordagens. 3a ed. Porto Alegre: Penso, 2014. Ver também: SEVERINO, Antônio Joaquim. Metodologia do Trabalho Científico. 24ạ ed. São Paulo: Cortez, 2016. 
vida, integridade e liberdade pessoal, garantia e proteção judicial (arts. 3, 4, 5, 7, 8 e 25 c/c 1.1 e 19 da Convenção).

A CortelDH sujeitou o Estado brasileiro a uma série de obrigações de reparação, aplicando o art. 63.1 da Convenção Americana ${ }^{2}$. No item 9 das Disposições, contidas nos Pontos Resolutivos da Sentença, foi determinado pela Corte que:

9. O Estado deve reiniciar, com a devida diligência, as investigações e/ou processos penais que correspondam pelos fatos constatados em março de 2000 no presente caso para, em um prazo razoável, identificar, processar e, como for o caso, sancionar aos responsáveis, de conformidade com o estabelecido nos parágrafos 444 a 446 da presente Sentença. Como for o caso, o Estado deve restabelecer (ou reconstruir) o processo penal 2001.39.01.0002700, iniciado em 2001, ante a 2a Vara da Justiça Federal de Marabá, Estado de Pará, de conformidade com o estabelecido nos parágrafos 444 a 446 da presente Sentença ${ }^{3}$.

2 COMISSÃO INTERAMERICANA DE DIREITOS HUMANOS. Convenção Americana de Direitos Humanos. Disponível em: <https://www.cidh.oas.org/basicos/portugues/c.convencao americana.htm>. Acesso em: 20 mar 2020. Art. 63.1: "Quando decidir que houve violação de um direito ou liberdade protegidos nesta Convenção, a Corte determinará que se assegure ao prejudicado o gozo do seu direito ou liberdade violados. Determinará também, se isso for procedente, que sejam reparadas as conseqüências da medida ou situação que haja configurado a violação desses direitos, bem como o pagamento de indenização justa à parte lesada."

3 CORTE INTERAMERICANA DE DIREITOS HUMANOS. Casos contenciosos. Disponível em: <https://www.corteidh.or.cr/cf/Jurisprudencia2/busqueda casos contenciosos.cfm?lang=es>. Acesso em: 20 mar 2020. O item X da sentença da CortelDH (Pontos Resolutivos) possuiu a seguinte redação, no original em espanhol: "X - PUNTOS RESOLUTIVOS. Por tanto, LA CORTE DECIDE, Por unanimidad,

1. Desestimar las excepciones preliminares interpuestas por el Estado relativas a la inadmisibilidad del sometimiento del caso a la Corte en virtud de la publicación del Informe de Fondo por parte de la Comisión; la incompetencia ratione personae, respecto de presuntas víctimas no identificadas, aquellas identificadas pero que no otorgaron poder de representación, que no aparecían en el Informe de Fondo de la Comisión o que no estaban relacionadas con los hechos del caso; la incompetencia ratione personae de violaciones en abstracto; la incompetencia ratione materiae por violación al principio de subsidiaridad del Sistema Interamericano (fórmula de la 4a instancia); la incompetencia ratione materiae relativa a presuntas violaciones de la prohibición de tráfico de personas; la incompetencia ratione materiae sobre supuestas violaciones de derechos laborales; la falta de agotamiento previo de los recursos internos, y la prescripción de la petición ante la Comisión respecto de las pretensiones de reparación de daño moral y material, en los términos de los párrafos 23 a 28, 44 a 50, 54, 71 a 74, 78 a 80, 84, 89 a 93 y 98 de la presente Sentencia.

2. Declarar parcialmente procedente la excepción preliminar interpuesta por el Estado relativa a la incompetencia ratione temporis respecto de hechos anteriores a la fecha de reconocimiento de la jurisdicción de la Corte por parte del Estado, y la incompetencia ratione temporis sobre hechos anteriores a la adhesión del Estado a la Convención Americana, en los términos de los párrafos 63 a 65 de la presente Sentencia.

DECLARA: Por unanimidad, que:

3. El Estado es responsable por la violación del derecho a no ser sometido a esclavitud y trata de personas, establecido en el artículo 6.1 de la Convención Americana sobre Derechos Humanos, en relación con los artículos 1.1, 3, 5, 7, 11 y 22 del mismo instrumento, en perjuicio de los 85 trabajadores rescatados el 15 de marzo de 2000 en la Hacienda Brasil Verde, listados en el párrafo 206 de la presente Sentencia, en los términos de los párrafos 342 y 343 de la presente Sentencia. Adicionalmente, respecto al señor Antônio Francisco da Silva esa violación ocurrió también en relación con el artículo 19 de la Convención Americana sobre Derechos Humanos, por ser niño al momento de los hechos, en los términos de los párrafos 342 y 343 de la presente Sentencia. 
Por cinco votos a favor y uno en contra, que:

4. El Estado es responsable por la violación del artículo 6.1 de la Convención Americana, en relación con el artículo 1.1 del mismo instrumento, producida en el marco de una situación de discriminación estructural histórica, en razón de la posición económica de los 85 trabajadores identificados en el párrafo 206 de la presente Sentencia, en los términos de los párrafos 342 y 343 de la presente Sentencia.

Disiente el Juez Sierra Porto.

Por unanimidad, que:

5. El Estado es responsable por violar las garantías judiciales de debida diligencia y de plazo razonable, previstas en el artículo 8.1 de la Convención Americana sobre Derechos Humanos, en relación con el artículo 1.1 del mismo instrumento, en perjuicio de los 43 trabajadores de la Hacienda Brasil Verde que se encontraron durante la fiscalización de 23 de abril de 1997 y que fueron identificados por la Corte en el párrafo 199 de la Sentencia, en los términos de los párrafos 361 a 382 de la presente Sentencia.

Por cinco votos a favor y uno en contra, que:

6. El Estado es responsable por violar el derecho a la protección judicial, previsto en el artículo 25 de la Convención Americana sobre Derechos Humanos, en relación con los artículos 1.1 y 2 del mismo instrumento en perjuicio de: a) los 43 trabajadores de la Hacienda Brasil Verde que se encontraron durante la fiscalización de 23 de abril de 1997 y que fueron identificados por la Corte en el presente litigio (supra párr. 199), y b) los 85 trabajadores de la Hacienda Brasil Verde que se encontraron durante la fiscalización de 15 de marzo de 2000 y que fueron identificados por la Corte en el presente litigio (supra párr. 206). Adicionalmente, en relación con el señor Antônio Francisco da Silva esa violación ocurrió en relación con el artículo 19 de la Convención Americana, todo lo anterior en los términos de los párrafos 383 a 420 de la presente Sentencia.

Disiente el Juez Sierra Porto.

Por unanimidad, que:

7. El Estado no es responsable por las violaciones a los derechos a la personalidad jurídica, vida, integridad y libertad personal, garantías y protección judiciales, contemplados en los artículos 3, 4, 5, 7, 8 y 25 de la Convención Americana, en relación con los artículos 1.1 y 19 del mismo instrumento, en perjuicio de Luis Ferreira da Cruz e Iron Canuto da Silva ni de sus familiares, en los términos de los párrafos 421 y 426 a 434 de la presente Sentencia.

Y DISPONE:

Por unanimidad, que:

8. Esta Sentencia constituye, per se, una forma de reparación.

9. El Estado debe reiniciar, con la debida diligencia, las investigaciones y/o procesos penales que correspondan por los hechos constatados en marzo de 2000 en el presente caso para, en un plazo razonable, identificar, procesar y, en su caso, sancionar a los responsables, de conformidad con lo establecido en los párrafos 444 a 446 de la presente Sentencia. En su caso, el Estado debe restablecer (o reconstruir) el proceso penal 2001.39.01.000270-0, iniciado en 2001, ante la 2a Vara de Justicia Federal de Marabá, Estado de Pará, de conformidad con lo establecido en los párrafos 444 a 446 de la presente Sentencia.

10. El Estado debe realizar en el plazo de seis meses, a partir de la notificación de la presente Sentencia, las publicaciones indicadas en el párrafo 450 de la Sentencia, en los términos dispuestos en la misma.

11. El Estado debe, dentro de un plazo razonable a partir de la notificación de la presente Sentencia, adoptar las medidas necesarias para garantizar que la prescripción no sea aplicada al delito de derecho internacional de esclavitud y sus formas análogas, en el sentido dispuesto en los párrafos 454 y 455 de la presente Sentencia.

12. El Estado debe pagar las cantidades fijadas en el párrafo 487 de la presente Sentencia, por concepto de indemnizaciones por daño inmaterial, y por el reintegro de costas y gastos, en los términos del párrafo 495 de la presente Sentencia.

13. El Estado debe, dentro del plazo de un año contado a partir de la notificación de esta Sentencia, rendir al Tribunal un informe sobre las medidas adoptadas para cumplir con la misma, sin perjuicio de lo establecido en el párrafo 451 de la presente Sentencia.

14. La Corte supervisará el cumplimiento íntegro de esta Sentencia, en ejercicio de sus atribuciones y en cumplimiento de sus deberes conforme a la Convención Americana sobre Derechos Humanos, y dará por concluido el presente caso una vez que el Estado haya dado cabal cumplimiento a lo dispuesto en la misma. 
A CortelDH estabeleceu que o não reconhecimento, no ordenamento interno brasileiro, do trabalho escravo enquanto crime imprescritível constituía um obstáculo relevante para a garantia da proteção judicial, seguindo o seu entendimento jurisprudencial de que graves violações de direitos humanos não prescrevem na esfera internacional.

Em relação ao senhor Antônio Francisco da Silva, houve violação em relação ao artigo 19 da Convenção Americana de Direitos Humanos ${ }^{4}$, por ser criança ao momento dos fatos.

No cumprimento da decisão, no ano de 2018, O Brasil atuou através do Ministério Público Federal, por meio da 2a Câmara de Coordenação e Revisão, bem como pela recém-criada Força Tarefa, mediante instauração de Procedimento Investigatório Criminal.

Esta atuação ministerial, entretanto, foi tida como ilegal pelos investigados, que impetraram Habeas Corpus junto ao Tribunal Regional Federal da $1^{a}$ Região (Habeas Corpus Criminal n. 1023279-03.2018.4.01.0000), sendo impetrado o Procurador da República no Município de Redenção/PA, e pacientes Joao Luiz Quagliato Neto e Antônio Jorge Vieira.

O Ministério Público Federal acatou a decisão (que reputaram os impetrantes incompatível com o ordenamento jurídico brasileiro), e instaurou um Procedimento Investigatório Criminal ("PIC" ou "Procedimento") para investigar os pacientes João Luiz Quagliato Neto e Antônio Jorge Vieira - proprietário e ex-funcionário da Fazenda, respectivamente, PIC este que pretenderam os impetrantes ver trancado.

Para os impetrantes, as determinações da Corte não poderiam ser aplicadas em confronto direto com a ordem constitucional brasileira. Dizem que a Corte Interamericana de Direitos Humanos, quando determinou a reabertura de investigação criminal contra os pacientes, era materialmente incompetente para fazê-lo, já que as decisões da Corte somente poderiam gerar efeitos para cidadãos brasileiros a partir da data em que o Brasil internalizou o reconhecimento da sua competência, o que ocorreu por meio do Decreto n.o 4.463 , de 8 de novembro de $2002^{5}$.

Los Jueces Eduardo Ferrer Mac-Gregor Poisot y Eduardo Vio Grossi dieron a conocer a la Corte sus votos individuales concurrentes. El Juez Humberto Antônio Sierra Porto dio a conocer a la Corte su voto individual parcialmente disidente.

Redactada en español y en portugués, haciendo fe el texto en español, en San José, Costa Rica, el día 20 de octubre de 2016.

4 CONVENÇÃO AMERICANA DE DIREITOS HUMANOS. Art. 19: "Toda criança tem direito às medidas de proteção que a sua condição de menor requer por parte da sua família, da sociedade e do Estado."

5 BRASIL. Decreto n.o 4.463, de 8 de novembro de 2002. Disponível em: <http://www.planalto.gov.br/ccivil 03/decreto/2002/D4463.htm>. Acesso em: 20 mar 2020. "DECRETO № 4.463, DE 8 DE NOVEMBRO DE 2002. Promulga a Declaração de Reconhecimento da Competência Obrigatória da Corte Interamericana de Direitos Humanos, sob reserva de reciprocidade, em consonância com o art. 62 da Convenção Americana sobre Direitos Humanos (Pacto de São José), de 22 de novembro de 1969. O PRESIDENTE DA REPÚBLICA, no uso da atribuição que lhe confere o art. 84, inciso IV, da Constituição, e Considerando que pelo Decreto no 678, de 6 de novembro de 1992, foi promulgada a Convenção Americana sobre Direitos Humanos (Pacto de São José), de 22 de novembro de 1969; Considerando que o Congresso Nacional aprovou, pelo Decreto Legislativo no 89, de 3 de dezembro de 1998, solicitação de reconhecimento da competência obrigatória da Corte Interamericana de Direitos Humanos, em todos os casos relativos à interpretação ou aplicação da Convenção, de acordo com o previsto no art. 62 daquele instrumento; Considerando que a Declaração de aceitação da competência obrigatória da Corte Interamericana de Direitos Humanos foi depositada junto à Secretaria-Geral da Organização dos Estados Americanos em 10 de dezembro de 1998, DECRETA: Art. 
Como os fatos ocorreram no ano 2000 , a decisão da Corte não seria oponível a cidadãos brasileiros, sob pena de violação do artigo 49, I, da Constituição Federal ${ }^{6}$.

Além disto, a sentença da Corte - com consequente determinação de responsabilização individual na esfera criminal - não teria respeitado o contraditório, a ampla defesa e a presunção de inocência, vez que os interessados não foram ouvidos durante os procedimentos que ensejaram a decisão internacional. Por seu turno, os alegados crimes investigados pelo PIC - ato coator - estariam prescritos segundo a lei brasileira, devendo ser reconhecida a extinção da punibilidade e determinado o trancamento da investigação. Assim, faltaria justa causa e interesse de agir ao procedimento, condições do inquérito e da ação penal.

Aduziram os impetrantes que a abertura de nova investigação a respeito dos mesmos fatos e a persecução dos mesmos indivíduos investigados no bojo do inquérito policial instaurado no ano 2000 caracterizaria bis in idem formal.

Diante do exposto, reclamaram os impetrantes a concessão de liminar para a suspensão do supracitado PIC até decisão de mérito do Habeas Corpus, e para ficarem igualmente suspensos todos os procedimentos, oitivas e trabalhos no contexto da ilegal investigação; e, no mérito, que fosse declarada extinta a punibilidade relativa aos fatos narrados, determinando-se o necessário trancamento do PIC; e, caso a denúncia fosse oferecida antes do julgamento do mandamus, o reconhecimento da continuidade do objeto da impetração e o necessário trancamento da ação penal.

A liminar foi indeferida, por ausência de elementos comprovados à sua concessão e necessidade de prévia coleta de informações.

As informações foram prestadas pelo órgão do MPF coator, e a Procuradoria Regional da República da 1ạ Região ofereceu parecer subscrito pelo membro do parquet Wellington Luís de Sousa Bonfim, opinando pela denegação da ordem.

Cabe analisar as questões suscitadas no julgamento, tal como o foram no acórdão produzido no âmbito da $4^{\mathrm{a}}$ Turma do Tribunal Regional Federal da $1^{\mathrm{a}}$ Região.

\section{Incompetência da CorteIDH para o julgamento do caso}

Foi alegada na impetração a incompetência da CortelDH para o julgamento do feito, já que as decisões da Corte somente poderiam gerar efeitos para cidadãos brasileiros a partir da data em que o Brasil internalizou o reconhecimento da sua competência, o que ocorreu por meio do Decreto n. .4 .463 , de 8 de novembro de 2002 (sendo os fatos datados do ano de 2000); e ocorrência de bis in idem formal.

Inicialmente, considerou-se no voto do Relator que a circunstância dos autos do procedimento aberto em 2001 (n. 2001.39.01.000270-0, iniciado ante a 2a Vara da Justiça Federal de Marabá, Estado de Pará) não terem sido localizados (extravio indicado

10 É reconhecida como obrigatória, de pleno direito e por prazo indeterminado, a competência da Corte Interamericana de Direitos Humanos em todos os casos relativos à interpretação ou aplicação da Convenção Americana de Direitos Humanos (Pacto de São José), de 22 de novembro de 1969, de acordo com art. 62 da citada Convenção, sob reserva de reciprocidade e para fatos posteriores a 10 de dezembro de 1998. Art. 2o Este Decreto entra em vigor na data de sua publicação. Brasília, 8 de novembro de 2002; 181ㅇ da Independência e 114ㅇ da República. FERNANDO HENRIQUE CARDOSO. Celso Lafer

6 BRASIL. Constituição Federal. Disponível em: <http://www.planalto.gov.br/ccivil 03/constituicao/ constituicaocompilado.htm>. Acesso em: 20 mar 2020. “Art. 49. É da competência exclusiva do Congresso Nacional: I - resolver definitivamente sobre tratados, acordos ou atos internacionais que acarretem encargos ou compromissos gravosos ao patrimônio nacional;" 
no item 185 da Sentença da Corte, a partir de informação recebida em 27.06.2016) em nada afetava a possibilidade de instauração do PIC que se pretendia ver trancado (PIC n. 1.23.005.000177/2017-62), na medida em que não havia notícia de denúncia (contra os pacientes) oferecida e recebida por juiz competente, sendo que uma investigação sempre pode ser reiniciada em novos autos (não existindo a necessidade de restauração de procedimento investigativo anterior).

Ademais, a CorteIDH assentou na Sentença de 26.10.1986 que a investigação e o processo penal deveriam ter curso perante a Justiça Federal brasileira, o que inviabilizaria a validade de quaisquer atos eventualmente produzidos na seara estadual paraense.

Como então visto acima, alegou a Inicial do Habeas Corpus que a Corte não seria competente para o julgamento da demanda, em razão da admissão da jurisdição internacional pelo Brasil haver sido posterior aos fatos, e por não caber o bis in idem investigativo.

Todavia, o art. 1으 do Decreto no 4.463/2002 (que promulgou a Declaração de Reconhecimento da Competência Obrigatória da Corte Interamericana de Direitos Humanos, em consonância com o art. 62 da Convenção Americana sobre Direitos Humanos - Pacto de São José -, de 22 de novembro de 1969) previu expressamente a admissão da jurisdição da Corte para fatos posteriores a 10 de dezembro de 1998, caso dos autos:

Art. 1 É reconhecida como obrigatória, de pleno direito e por prazo indeterminado, a competência da Corte Interamericana de Direitos Humanos em todos os casos relativos à interpretação ou aplicação da Convenção Americana de Direitos Humanos (Pacto de São José), de 22 de novembro de 1969, de acordo com art. 62 da citada Convenção, sob reserva de reciprocidade e para fatos posteriores a 10 de dezembro de 1998.

Diante dos termos em que admitida a jurisdição da Corte pelo Brasil, coube afastar a alegação de incompetência material do órgão internacional para determinar a reabertura de investigação criminal contra os pacientes. Os fatos foram praticados em março de 2000 e a Corte possui jurisdição sobre o Brasil para fatos praticados desde 10 de dezembro de 1998, momento em que o Estado brasileiro comunicou à OEA sua decisão de aderir à jurisdição da CorteIDH (e quando surge a obrigação internacional para o país).

E, apreciando a inaplicabilidade da prescrição ao caso concreto, como se verá abaixo, é evidente exercer a CortelDH sua competência sobre a questão, prevista na Convenção Americana, não representando isto qualquer bis in idem indevido, e sim a concretização da previsão constitucional de jurisdição de tribunal internacional de direitos humanos sobre o Estado brasileiro (ADCT/CF88, Art. 70: "O Brasil propugnará pela formação de um tribunal internacional dos direitos humanos" ${ }^{77}$ ).

7 BRASIL. Constituição Federal. Disponível em: <http://www.planalto.gov.br/ccivil 03/ constituicao/constituicaocompilado.htm>. Acesso em: 20 mar 2020. 


\section{Violação ao contraditório, à ampla defesa e à presunção de inocência}

Outra alegação da impetração consistiu na suposta violação ao contraditório, à ampla defesa e à presunção de inocência, na medida em que os indiciados não foram ouvidos na CortelDH durante os procedimentos que ensejaram a decisão internacional e nem puderam ali deduzir argumentos de defesa.

Ocorre, todavia, como disse a manifestação ministerial no segundo grau, que o contraditório a ser exercido em cortes internacionais se dirige unicamente aos estados nacionais, que ali são eventuais responsabilizados. Não há julgamento de indivíduos pela Corte Interamericana de Direitos Humanos, nos termos dos artigos 61, 62 e 63 da Convenção Americana de Direitos Humanos ${ }^{8}$.

O Estado condenado, então, deve passar a garantir a aplicação da decisão internacional, de modo que o contraditório, a presunção de inocência e a ampla defesa a ser respeitados em relação aos impetrantes se referem ao âmbito de eventual ação penal ajuizada perante o Poder Judiciário nacional.

Os pacientes não foram responsabilizados pela Sentença da CorteIDH. A responsabilização incidiu sobre o Brasil que exerceu, perante aquela Corte, o contraditório e a ampla defesa, inclusive arguindo diversas preliminares e expondo argumentos de mérito.

\section{A inadmissibilidade da prescrição da ação penal em violações graves aos direitos humanos}

Por fim, foi alegada a impossibilidade de afastamento, no plano interno brasileiro, da ocorrência da prescrição.

Segundo a impetração (no Habeas Corpus mencionado):

Considerando que a pena máxima em abstrato do delito de reduzir alguém a condição análoga à de escravo é de 8 anos (art.

8 COMISSÃO INTERAMERICANA DE DIREITOS HUMANOS. Convenção Americana de Direitos Humanos. Disponível em: <https://www.cidh.oas.org/basicos/portugues/c.convencao americana.htm>. Acesso em: 20 mar 2020. Artigo 61. 1: "Somente os Estados Partes e a Comissão têm direito de submeter caso à decisão da Corte. 2. Para que a Corte possa conhecer de qualquer caso, é necessário que sejam esgotados os processos previstos nos artigos 48 a 50. Artigo 62 1. Todo Estado Parte pode, no momento do depósito do seu instrumento de ratificação desta Convenção ou de adesão a ela, ou em qualquer momento posterior, declarar que reconhece como obrigatória, de pleno direito e sem convenção especial, a competência da Corte em todos os casos relativos à interpretação ou aplicação desta Convenção. 2. A declaração pode ser feita incondicionalmente, ou sob condição de reciprocidade, por prazo determinado ou para casos específicos. Deverá ser apresentada ao Secretário-Geral da Organização, que encaminhará cópias da mesma aos outros Estados membros da Organização e ao Secretário da Corte. 3. A Corte tem competência para conhecer de qualquer caso relativo à interpretação e aplicação das disposições desta Convenção que lhe seja submetido, desde que os Estados Partes no caso tenham reconhecido ou reconheçam a referida competência, seja por declaração especial, como prevêem os incisos anteriores, seja por convenção especial. Artigo 63 1. Quando decidir que houve violação de um direito ou liberdade protegidos nesta Convenção, a Corte determinará que se assegure ao prejudicado o gozo do seu direito ou liberdade violados. Determinará também, se isso for procedente, que sejam reparadas as conseqüências da medida ou situação que haja configurado a violação desses direitos, bem como o pagamento de indenização justa à parte lesada. 2. Em casos de extrema gravidade e urgência, e quando se fizer necessário evitar danos irreparáveis às pessoas, a Corte, nos assuntos de que estiver conhecendo, poderá tomar as medidas provisórias que considerar pertinentes. Se se tratar de assuntos que ainda não estiverem submetidos ao seu conhecimento, poderá atuar a pedido da Comissão." 
149, Código Penal), a prescrição dos alegados fatos ocorridos em março de 2000 se deu em março de 2012 (art. 109, III, Código Penal). Todos os outros delitos possivelmente atribuíveis à mesma situação (vide art. 197 e 207, Código Penal) apresentam penas menores e, portanto, também já prescreveram."

Em que pesem os dados prescricionais, o Ministério Público Federal requereu, em 30 de junho de 2017, a instauração de um Procedimento Investigatório Criminal para investigar os fatos ocorridos em março de 2000. O MPF, então, decidiu não restaurar o inquérito policial desaparecido, e sim iniciar um novo, tendo em vista o "grande lapso temporal desde a última notícia que se tem do procedimento".

O Estado brasileiro teve 17 anos para investigar os fatos supostamente ocorridos em 2000, e não o fez. Se, por um lado, eles não tiveram a possibilidade de provar sua inocência por longos anos de incerteza até a ocorrência da prescrição, hoje sofrem investigação absurda por fatos já prescritos.

O Supremo Tribunal Federal, inclusive, já consolidou o entendimento de que a alegada "imprescritibilidade" determinada por cortes estrangeiras em nada afeta o ordenamento jurídico interno, o qual permanece considerando imprescritíveis somente os delitos que assim são tratados pela Constituição Federal.

(...) eventual execução teria findado ainda no ano 2000.

A Súmula 524 do STF estabelece que uma vez arquivado o inquérito policial por despacho do juiz ou a requerimento do promotor de justiça, não pode a ação penal ser iniciada sem novas provas.

A prescrição é um verdadeiro princípio do Código Penal Brasileiro, o qual, porém, possui caráter de materialidade constitucional. Tanto é assim que os crimes imprescritíveis no nosso ordenamento surgem como exceções no nosso sistema penal e possuem assento constitucional - é o caso do racismo (CF, art. $5^{\circ}$, XLII) e da atuação de grupos armados contra a ordem constitucional e o Estado Democrático (CF, art. 5ㅇ, XLIV) ${ }^{9}$.

Sobre o tema, cabe aduzir que a proibição de escravidão é prevista na Convenção Americana de Direitos Humanos (CADH), adotada pelo Brasil desde 1992, e esta regra não pode ser suspensa nem mesmo em caso de guerra, de perigo público, ou de outra emergência que ameace a independência ou segurança do Estado Parte (art. 27). 0 Brasil se comprometeu a combater este ilícito, como se vê também na Convenção OIT n. 105 (Convenção Relativa a Abolição do Trabalho Forçado), adotada em 25 de junho de 1957, e que teve entrada em vigor em 17 de janeiro de 1959, sendo que o Estado brasileiro ratificou a Convenção em 18 de junho de 1965.

A partir do primeiro tratado universal sobre a eliminação da escravidão (Convenção sobre a Escravatura, adotada em Genebra, em 25 de setembro de 1926), vários tratados internacionais têm reiterado a proibição da escravidão, a qual é

9 Vide relatório do julgado. BRASIL. Tribunal Regional Federal da 1a Região. Jurisprudência. Disponível em: <https://www2.cjf.jus.br/jurisprudencia/trf1/index.xhtml>. Acesso em: 20 mar 2020. 
considerada uma norma imperativa do Direito Internacional (jus cogens), e implica obrigações erga omnes de acordo com a Corte Internacional de Justiça ${ }^{10}$.

É inegável o status jurídico internacional da proibição da escravidão. Além disso, tanto o Brasil como a maioria dos estados da região são parte da Convenção sobre a Escravatura de 1926 e da Convenção Suplementar sobre a Abolição da Escravatura de 1956.

Nos casos de escravidão, a prescrição da ação penal é inadmissível e inaplicável, pois esta não se aplica quando se trata de violações muito graves aos direitos humanos, nos termos do Direito Internacional. A jurisprudência constante e uniforme da Corte Internacional de Justiça e da CorteIDH assim o estabeleceu ${ }^{11}$.

Na sentença contra o Brasil, assim se manifestou a CortelDH:

412. A Corte já indicou que a prescrição em matéria penal determina a extinção da pretensão punitiva em virtude do transcurso do tempo e, geralmente, limita o poder punitivo do Estado para perseguir a conduta ilícita e sancionar seus autores. Esta é uma garantia que deve ser devidamente observada pelo julgador para todo acusado de um delito. Sem prejuízo do anterior, a prescrição da ação penal é inadmissível quando assim o dispõe o Direito Internacional. Neste caso, a escravidão é considerada um delito de Direito Internacional, cuja proibição tem status de jus cogens (par. 249 supra). Além disso, a Corte indicou que não é admissível a invocação de figuras processuais como a prescrição, para evadir a obrigação de investigar e punir estes delitos. Para que o Estado satisfaça o dever de garantir adequadamente diversos direitos protegidos na Convenção, entre eles o direito de acesso à justiça, é necessário que cumpra seu dever de investigar, julgar e, se for o caso, punir estes fatos e reparar os danos causados. Para alcançar esse fim, o Estado deve observar o devido processo e garantir, entre outros, o princípio de prazo razoável, os recursos efetivos e o cumprimento da sentença. 413. A Corte já estabeleceu que: i) a escravidão e suas formas análogas constituem um delito de Direito Internacional, ii) cuja proibição pelo Direito Internacional é uma norma de jus cogens (par. 249 supra). Portanto, a Corte considera que a prescrição dos delitos de submissão à condição de escravo e suas formas análogas é incompatível com a obrigação do Estado brasileiro de adaptar sua normativa interna de acordo aos padrões internacionais. No presente caso a aplicação da prescrição constituiu um obstáculo para a investigação dos fatos, para a determinação e punição dos responsáveis e para a reparação das vítimas, apesar do caráter de delito de Direito Internacional que os fatos denunciados representavam." (Tradução nossa).. ${ }^{12}$

10 RAMOS, André de Carvalho. Curso de Direitos Humanos. $7^{\mathrm{a}}$ ed. São Paulo: Saraiva, 2020, p.181.

11 CORTE INTERAMERICANA DE DIREITOS HUMANOS. Casos contenciosos. Disponível em: $<$ https://www.corteidh.or.cr/cf/Jurisprudencia2/busqueda casos contenciosos.cfm?lang=es>. Acesso em: 20 mar 2020. vide Caso Albán Cornejo y otros. Vs. Ecuador. Mérito, Reparações e Custas. Sentença de 22 de novembro de 2007. Série C No. 171. Par. 111. Ver também, CortelDH. Relatório da CortelDH, par. 221

12 Ibid. 
Por seu turno, a norma invocada para fundamentar a ocorrência da prescrição é de índole legal (DL 2.848/40, Código Penal - art. 109, III), e desde o julgamento do RE 466.343/SP pelo Supremo Tribunal Federal (j. 03.12.2008 - vide também, julgado na mesma data, o RE 349.703/RS), as normas internacionais sobre direitos humanos possuem, no caso de não observância do rito previsto no par. $3^{\circ}$ do art. $5^{\circ}$ da CF (hipótese que conferiria status constitucional à norma), a hierarquia supralegal.

O julgamento se referiu aos tratados internacionais, normas de natureza obrigatória, mas o raciocínio deve ser empregado em relação aos princípios gerais de direito internacional e aos costumes internacionais, quando ostentem a mesma natureza cogente (jus cogens).

É certo que alguns prefiram entender que normas internacionais de proteção aos direitos humanos possuam sempre status de "norma constitucional" ${ }^{13}$, mas esta compreensão não prevalece, e nem se faz sempre necessária. Caso a prescritibilidade fosse trazida por norma constitucional brasileira, a solução poderia consistir na utilização da norma mais benéfica, em se tratando de direitos humanos, ${ }^{14}$ ou tratar a norma interna como materialmente inconstitucional ${ }^{15}$.

Desta forma, no caso de violação a normas internacionais relativas a direitos humanos, as normas prescricionais, por serem, no caso, de índole infraconstitucional e legal, não podem merecer qualquer aplicação por parte do operador jurídico brasileiro. Reconhecer a ocorrência da prescrição significaria afastar normas internacionais já internalizadas e vigentes no ordenamento brasileiro, possuidoras de hierarquia superior, 0 que não pode ocorrer.

Tal entendimento, adotado pelo STF, já resultou na edição da Súmula Vinculante 25 , no sentido de que "é ilícita a prisão civil de depositário infiel, qualquer que seja a modalidade de depósito", sendo o precedente representativo explícito no sentido de que:

(...) diante do inequívoco caráter especial dos tratados internacionais que cuidam da proteção dos direitos humanos, não é difícil entender que a sua internalização no ordenamento jurídico, por meio do procedimento de ratificação previsto na CF88, tem o condão de paralisar a eficácia jurídica de toda e qualquer disciplina normativa infraconstitucional com ela conflitante. Nesse sentido, é possível concluir que, diante da supremacia da CF88 sobre os atos normativos internacionais, a previsão constitucional da prisão civil do depositário infiel (art. 5o, LXVII) não foi revogada (...), mas deixou de ter aplicabilidade diante do efeito paralisante desses tratados em relação à legislação infraconstitucional que disciplina a matéria (...). Tendo em vista o caráter supralegal desses diplomas normativos internacionais, a legislação infraconstitucional posterior que com eles seja conflitante também tem sua eficácia paralisada. (...) Enfim, desde a adesão do Brasil, no ano de 1992, ao PIDCP

13 MAZZUOLI, Valério de Oliveira. Direito Internacional: Tratados e Direitos Humanos fundamentais na ordem jurídica brasileira. Rio de Janeiro: América Jurídica, 2001, p. 150.

14 PINHEIRO, Carla. Direito Internacional e Direitos Fundamentais. São Paulo: Atlas, 2001, p. 77.

15 BACHOF, Otto. Normas Constitucionais Inconstitucionais. Coimbra: Almedina, 1994. Para Bachof, uma norma constitucional pode ser nua, se desrespeitar em medida insuportável os postulados fundamentais da Justiça (p. 3). 
(art. 11) e à CADH - Pacto de São José da Costa Rica (art. 70, 7), não há base legal para aplicação da parte final do art. 5, LXVII, da CF/1988, ou seja, para a prisão civil do depositário infiel. (RE 466.343, voto do rel. min. Cezar Peluso, P, j. 3-122008, DJE 104 de 5-6-2009, Tema 60.)

A matéria em julgamento neste habeas corpus envolve a temática da (in)admissibilidade da prisão civil do depositário infiel no ordenamento jurídico brasileiro no período posterior ao ingresso do Pacto de São José da Costa Rica no direito nacional. 2. Há o caráter especial do PIDCP (art. 11) e da CADH - Pacto de São José da Costa Rica (art. 70, 7), ratificados, sem reserva, pelo Brasil, no ano de 1992. A esses diplomas internacionais sobre direitos humanos é reservado o lugar específico no ordenamento jurídico, estando abaixo da CF/1988, porém acima da legislação interna. O status normativo supralegal dos tratados internacionais de direitos humanos subscritos pelo Brasil torna inaplicável a legislação infraconstitucional com ele conflitante, seja ela anterior ou posterior ao ato de ratificação. $3 . \mathrm{Na}$ atualidade a única hipótese de prisão civil, no Direito brasileiro, é a do devedor de alimentos. O art. 5ㅇ $\S 2 \circ$, da Carta Magna expressamente estabeleceu que os direitos e garantias expressos no caput do mesmo dispositivo não excluem outros decorrentes do regime dos princípios por ela adotados, ou dos tratados internacionais em que a República Federativa do Brasil seja parte. O Pacto de São José da Costa Rica, entendido como um tratado internacional em matéria de direitos humanos, expressamente, só admite, no seu bojo, a possibilidade de prisão civil do devedor de alimentos e, consequentemente, não admite mais a possibilidade de prisão civil do depositário infiel. 4. Habeas corpus concedido. (HC 95.967, rel. min. Ellen Gracie, 2a T, j. 11-11-2008, DJE 227 de 28-112008. $)^{16}$.

A supralegalidade vem sendo reafirmada em sede de controle concentrado oponível erga omnes também através do instrumento de ações diretas de inconstitucionalidade:

Esse caráter supralegal do tratado devidamente ratificado e internalizado na ordem jurídica brasileira - porém não submetido ao processo legislativo estipulado pelo art. 5으, § 3으, da CF/1988 foi reafirmado pela edição da Súmula Vinculante 25 , segundo a qual "é ilícita a prisão civil de depositário infiel, qualquer que seja a modalidade do depósito". Tal verbete sumular consolidou o entendimento deste Tribunal de que 0 art. 70, item 7, da CADH teria ingressado no sistema jurídico nacional com status supralegal, inferior à $\mathrm{CF} / 1988$ mas superior à legislação interna, a qual não mais produziria qualquer efeito naquilo que conflitasse com a sua disposição de vedar a prisão civil do depositário infiel. Tratados e convenções

16 BRASIL. Supremo Tribunal Federal. Jurisprudência. Disponível em: <https://www2.cjf.jus.br/jurisprudencia/stf/index.xhtml>. Acesso em: 20 mar 2020. 
internacionais com conteúdo de direitos humanos, uma vez ratificados e internalizados, ao mesmo passo em que criam diretamente direitos para os indivíduos, operam a supressão de efeitos de outros atos estatais infraconstitucionais que se contrapõem à sua plena efetivação. (ADI 5.240, voto do rel. min. Luiz Fux, P, j. 20-8-2015, DJE 18 de 10-2-2016. $)^{17}$.

Não há como se acolher o argumento de que a Constituição limitou os casos de imprescritibilidade aos crimes que indicou (racismo - art. $5^{\circ}$, XLII, e de atuação de grupos armados contra a ordem constitucional e o Estado Democrático - art. 5으, XLIV), pois tanto há a abertura constitucional para outras normas de direitos fundamentais oriundas da esfera internacional (art. $5^{\circ}, \S 2$ : $:$ Os direitos e garantias expressos nesta Constituição não excluem outros decorrentes do regime e dos princípios por ela adotados, ou dos tratados internacionais em que a República Federativa do Brasil seja parte) - caso da imprescritibilidade dos crimes contra direitos humanos, quanto não deve haver a interpretação de que a imprescritibilidade prejudique direitos fundamentais e deva ser interpretada restritivamente, na medida em que a mesma é neutra em relação aos direitos individuais (já que a inocorrência da prescrição tanto limita direitos fundamentais quanto os assegura, ao garantir a prevenção e a repressão a delitos). Daí a possibilidade do rol de delitos imprescritíveis ser alargado, seja por lei ordinária, seja por tratado internacional ${ }^{18}$.

Por isto mesmo, no Recurso Extraordinário 460.971/RS, o STF já decidiu expressamente que "a Constituição Federal se limita, no art. 50, XLII e XLIV, a excluir os crimes que enumera da incidência material das regras de prescrição, sem proibir, em tese, que a legislação ordinária criasse outras hipóteses" ${ }^{19}$. E, no caso, tem-se a criação da imprescritibilidade por normas de hierarquia supralegal, e sem qualquer ofensa à Constituição Federal.

\section{O Habeas Corpus Criminal n. 1023279-03.2018.4.01.0000 e o cumprimento da ordem emitida pela CortelDH}

Analisados cada um dos argumentos contidos na petição inicial do Habeas Corpus Criminal n. 1023279-03.2018.4.01.0000, impetrado junto ao Tribunal Regional Federal da $1^{a}$ Região, não restou ao final qualquer espaço para se entender presente a possibilidade de acolhimento das teses de incompetência da CorteIDH para o julgamento do feito; de violação ao contraditório, à ampla defesa e à presunção de inocência; bem como de ocorrência da prescrição dos delitos investigados. Deste modo, a ordem foi denegada pelo Relator, julgamento adotado por maioria no âmbito da $4^{\mathrm{a}}$ Turma do TRF da $1^{\mathrm{a}}$ Região $^{20}$.

\section{Ibid.}

18 BAHIA, Saulo José Casali. O Tribunal Penal Internacional sob as perspectivas internacional e brasileira. In Direito Internacional \& as novas disciplinarizações. FERREIRA JUNIOR, Lier Pires \& ARAÚJO, Luis Ivani de Amorim, Organizadores. Curitiba: Juruá, 2005, p. 292.

19 BRASIL. Supremo Tribunal Federal. Jurisprudência. Disponível em: $<$ https://www2.cjf.jus.br/jurisprudencia/stf/index.xhtml >. Acesso em: 20 mar 2020.

20 BRASIL. Tribunal Regional Federal da 1ạ Região. Jurisprudência. Disponível em: <https://www2.cjf.jus.br/jurisprudencia/trf1/index.xhtml>. Acesso em: 20 mar 2020. "PENAL. PEDIDO DE TRANCAMENTO DE PROCESSO INVESTIGATÓRIO CRIMINAL, CUJA ABERTURA FOI DETERMINADA PELA CORTE INTERAMERICANA DE DIREITOS HUMANOS. CASO TRABALHADORES DA FAZENDA BRASIL VERDE CONTRA A REPÚBLICA FEDERATIVA DO BRASIL. COMPETÊNCIA DA CIDH. INEXISTÊNCIA DE PRÉVIA OITIVA DOS PACIENTES. JURISDIÇÃO DA CIDH SOBRE ESTADOS, E NÃO SOBRE INDIVÍDUOS. AUSÊNCIA DE 
VIOLAÇÃO AO CONTRADITÓRIO, À PRESUNÇÃO DE INOCÊNCIA E À AMPLA DEFESA. TRABALHO ESCRAVO. CRIME CONTRA OS DIREITOS HUMANOS. IMPRESCRITIBILIDADE. ORDEM DENEGADA 1.0 art. 10 do Decreto no 4.463/2002 (que promulgou a Declaração de Reconhecimento da Competência Obrigatória da Corte Interamericana de Direitos Humanos, em consonância com o art. 62 da Convenção Americana sobre Direitos Humanos - Pacto de São José -, de 22 de novembro de 1969) previu expressamente a admissão da jurisdição da Corte para fatos posteriores a 10 de dezembro de 1998, caso dos autos. 2. 0 contraditório a ser exercido em cortes internacionais se dirige unicamente aos estados nacionais, que ali são eventuais responsabilizados. Não há julgamento de indivíduos pela Corte Interamericana de Direitos Humanos, nos termos dos artigos 61, 62 e 63 da Convenção Americana de Direitos Humanos. 0 estado condenado, então, deve passar a garantir a aplicação da decisão internacional, de modo que o contraditório, a presunção de inocência e a ampla defesa a ser respeitados em relação aos impetrantes se referem ao âmbito de eventual ação penal ajuizada perante o Poder Judiciário nacional. Os pacientes não foram responsabilizados pela Sentença da $\mathrm{CIDH}$. A responsabilização incidiu sobre o Brasil que exerceu, perante aquela Corte, o contraditório e a ampla defesa, inclusive arguindo diversas preliminares e expondo argumentos de mérito. 3. A proibição de escravidão é prevista na Convenção Americana de Direitos Humanos (CADH), adotada pelo Brasil desde 1992, e esta regra não pode ser suspensa nem mesmo em caso de guerra, de perigo público, ou de outra emergência que ameace a independência ou segurança do Estado Parte (art. 27). O Brasil se comprometeu a combater este ilícito, como se vê também na Convenção OIT n. 105 (Convenção Relativa a Abolição do Trabalho Forçado), adotada em 25 de junho de 1957, e que teve entrada em vigor em 17 de janeiro de 1959, sendo que o Estado brasileiro ratificou a Convenção em 18 de junho de 1965. A partir do primeiro tratado universal sobre a eliminação da escravidão (Convenção sobre a Escravatura, adotada em Genebra, em 25 de setembro de 1926), vários tratados internacionais têm reiterado a proibição da escravidão, a qual é considerada uma norma imperativa do Direito Internacional (jus cogens), e implica obrigações erga omnes de acordo com a Corte Internacional de Justiça. É inegável o status jurídico internacional da proibição da escravidão. Além disso, tanto o Brasil como a maioria dos estados da região são parte da Convenção sobre a Escravatura de 1926 e da Convenção Suplementar sobre a Abolição da Escravatura de 1956. 4. Nos casos de escravidão, a prescrição da ação penal é inadmissível e inaplicável, pois esta não se aplica quando se trata de violações muito graves aos direitos humanos, nos termos do Direito Internacional. A jurisprudência constante e uniforme da Corte Internacional de Justiça e da CIDH, como indicado pelo MPF, assim o estabeleceu (vide Caso Albán Cornejo y otros. Vs. Ecuador. Mérito, Reparações e Custas. Sentença de 22 de novembro de 2007. Série C No. 171. Par. 111. Ver também, $\mathrm{CIDH}$. Relatório da $\mathrm{CIDH}$, par. 221). 5. A norma invocada para fundamentar a ocorrência da prescrição é de índole legal (DL 2.848/40, Código Penal - art. 109, III), e desde o julgamento do RE 466.343/SP pelo Supremo Tribunal Federal (j. 03.12.2008 - vide também, julgado na mesma data, o RE 349.703/RS), as normas internacionais sobre direitos humanos possuem, no caso de não observância do rito previsto no par. $3^{\circ}$ do art. $5^{\circ}$ da CF (hipótese que conferiria status constitucional à norma), a hierarquia supralegal. O julgamento se referiu aos tratados internacionais, normas de natureza obrigatória, mas o raciocínio deve ser empregado em relação aos princípios gerais de direito internacional e aos costumes internacionais, quando ostentem a mesma natureza cogente (jus cogens). 6. Desta forma, no caso de violação a normas internacionais relativas a direitos humanos, as normas prescricionais, por serem, no caso, de índole infraconstitucional e legal, não podem merecer qualquer aplicação por parte do operador jurídico brasileiro. Reconhecer a ocorrência da prescrição significaria afastar normas internacionais já internalizadas e vigentes no ordenamento brasileiro, possuidoras de hierarquia superior, o que não pode ocorrer. Tal entendimento, adotado pelo STF, já resultou na edição da Súmula Vinculante 25 , no sentido de que "é ilícita a prisão civil de depositário infiel, qualquer que seja a modalidade de depósito". 7. Não há como se acolher o argumento de que a Constituição limitou os casos de imprescritibilidade aos crimes que indicou (racismo - art. $5^{\circ}$, XLII, e de atuação de grupos armados contra a ordem constitucional e o Estado Democrático - art. 5o, XLIV), pois tanto há a abertura constitucional para outras normas de direitos fundamentais oriundas da esfera internacional (art. $5^{\circ}, \S$ 20: Os direitos e garantias expressos nesta Constituição não excluem outros decorrentes do regime e dos princípios por ela adotados, ou dos tratados internacionais em que a República Federativa do Brasil seja parte) - caso da imprescritibilidade dos crimes contra direitos humanos, quanto não deve haver a interpretação de que a imprescritibilidade prejudique direitos fundamentais e deva ser interpretada restritivamente, na medida em que a mesma é neutra em relação aos direitos individuais (já que a inocorrência da prescrição tanto limita direitos fundamentais quanto os assegura, ao garantir a 
O acórdão acima transitou em julgado em 16/07/2019, após o julgamento dos embargos de declaração interpostos.

O julgamento acima representa o cumprimento da ordem emitida pela Corte Interamericana de Direitos Humanos para que o Estado brasileiro reabrisse investigação para averiguar fatos ocorridos no ano de 2000 na Fazenda Brasil Verde.

O destaque deste julgamento, sem dúvida alguma, se relaciona à nova interpretação sobre a prescrição, reconhecida inicialmente no plano interno (primeiro grau de jurisdição) e afastada tanto pela CortelDH (ao julgar o caso Fazenda Brasil Verde) quanto pelo TRF da $1^{\text {a }}$ Região ao apreciar o Habeas Corpus Criminal n. 1023279-03.2018.4.01.0000.

\section{Conclusão}

Como se viu, o afastamento da prescrição tanto derivou da hegemonia sobre o direito interno que se deu às normas internacionais que proíbem o advento da prescrição, sob o argumento de integrarem o jus cogens (direito cogente) internacional, quanto da hierarquia de tratados internacionais introduzidos no plano interno brasileiro, quando, na esteira da jurisprudência do Supremo Tribunal Federal, se reconhece o status supralegal aos mesmos.

Graves violações de direitos humanos não podem ser afastadas sob o argumento da prescrição, ainda que este instituto pertença ao ordenamento jurídico interno de qualquer Estado.

No caso concreto, inclusive, a questão não careceu ser confrontada com o plano constitucional brasileiro, por não ser a prescrição tratada em norma interna de tal hierarquia. Caso a prescritibilidade fosse trazida por norma constitucional brasileira, a solução poderia consistir na utilização da norma mais benéfica, em se tratando de direitos humanos, ou tratar a norma interna como materialmente inconstitucional.

Por seu turno, foi reafirmada a jurisprudência da CorteIDH de que processos em cortes internacionais prescindem do contraditório e ampla defesa em relação a particulares. Trata-se de preliminar costumeiramente considerada em diversos outros processos da CortelDH, a partir do fato de que indivíduos não foram ouvidos na CortelDH durante os procedimentos que ensejaram a decisão internacional e nem puderam ali deduzir argumentos de defesa ${ }^{21}$.

Todavia, o contraditório a ser exercido em cortes internacionais se dirige unicamente aos estados nacionais, que ali são eventuais responsabilizados. Não há julgamento de indivíduos pela Corte Interamericana de Direitos Humanos, nos termos dos artigos 61, 62 e 63 da Convenção Americana de Direitos Humanos.

prevenção e a repressão a delitos). Por isto mesmo, no Recurso Extraordinário 460.971/RS, o STF já decidiu expressamente que "a Constituição Federal se limita, no art. 5ㅇ, XLII e XLIV, a excluir os crimes que enumera da incidência material das regras de prescrição, sem proibir, em tese, que a legislação ordinária criasse outras hipóteses". E, no caso, tem-se a criação da imprescritibilidade por normas de hierarquia supralegal, e sem qualquer ofensa à Constituição Federal. 8. Ordem denegada. (Acórdão, Decide a Turma, por maioria, denegar a ordem de habeas corpus. TRF da 1ạ Região, 4ạ Turma. DOU de 11 de dezembro de 2018. Relator convocado Saulo Casali Bahia).

21 Inventariando estes casos, veja-se SILVA, Lucas Gonçalves; SOUZA, Ana Paula de Jesus. Análise dos casos brasileiros na corte interamericana de direitos humanos: ascensão do transconstitucionalismo? In Revista do Programa de Pós-Graduação em Direito da UFBA, e-issn 2358-4777, V. 29, N. 01, ps 98-111, Jan-Jun 2019. 
O Estado condenado, então, deve passar a garantir a aplicação da decisão internacional, de modo que o contraditório, a presunção de inocência e a ampla defesa a ser respeitados em relação aos indivíduos responsáveis se referem ao âmbito de eventual ação penal ajuizada perante o Poder Judiciário nacional. Os pacientes não foram responsabilizados pela Sentença da CorteIDH. A responsabilização incidiu sobre o Brasil que exerceu, perante aquela Corte, o contraditório e a ampla defesa, inclusive arguindo diversas preliminares e expondo argumentos de mérito.

Mais uma vez, a Corte proclamou o direito a julgamento, no plano interno, em prazo razoável, e o direito de todos à proteção judicial, em processo eficaz, e que, se violado, pode levar à sua atuação complementar. Não foi a primeira vez que a complementariedade exsurgiu de omissão deste tipo. O próprio Brasil já havia sofrido condenações por omissões similares verificadas nos casos Ximenes Lopes e Gomes Lund.

E mais uma vez reafirmou-se, contra o Brasil, ser irrelevante que admissão da jurisdição internacional houvesse sido posterior aos fatos, já que o art. 10 do Decreto no 4.463/2002 (que promulgou a Declaração de Reconhecimento da Competência Obrigatória da Corte Interamericana de Direitos Humanos, em consonância com o art. 62 da Convenção Americana sobre Direitos Humanos - Pacto de São José -, de 22 de novembro de 1969) previu expressamente a admissão da jurisdição da Corte para fatos posteriores a 10 de dezembro de 1998, caso dos autos, quando os fatos foram praticados em março de 2000.

Sem dúvida alguma, o julgamento do Caso Fazenda Brasil Verde, pela CorteIDH, representa um avanço na proteção dos direitos humanos em escala hemisférica. As matérias tratadas certamente voltarão a ser agitadas em casos futuros, mas as soluções já se encontram antevistas pela jurisprudência consolidada da Corte, construída na premissa de que a defesa dos direitos humanos é um processo gradual, evolutivo e constante.

\section{Referências}

BACHOF, Otto. Normas Constitucionais Inconstitucionais. Coimbra: Almedina, 1994.

BAHIA, Saulo José Casali. O Tribunal Penal Internacional sob as perspectivas internacional e brasileira. In Direito Internacional \& as novas disciplinarizações. FERREIRA JUNIOR, Lier Pires \& ARAÚJO, Luis Ivani de Amorim, Organizadores. Curitiba: Juruá, 2005.

BRASIL. Constituição Federal. Disponível em: $<$ http://www.planalto.gov.br/ccivil 03/constituicao/constituicaocompilado.htm $>$. Acesso em: 20 mar 2020.

BRASIL. Decreto n. 4.463, de 8 de novembro de 2002. Disponível em: $<$ http://www.planalto.gov.br/ccivil 03/decreto/2002/D4463.htm>. Acesso em: $20 \mathrm{mar}$ 2020.

BRASIL. Supremo Tribunal Federal. Jurisprudência. Disponível em: <https://www2.cjf.jus.br/jurisprudencia/stf/index.xhtml>. Acesso em: 20 mar 2020.

BRASIL. Tribunal Regional Federal da 1a Região. Jurisprudência. Disponível em: <https://www2.cjf.jus.br/jurisprudencia/trf1/index.xhtml>. Acesso em: 20 mar 2020.

COMISSÃO INTERAMERICANA DE DIREITOS HUMANOS. Convenção Americana de Direitos

Humanos. Disponível em: <https://www.cidh.oas.org/basicos/portugues/ c.convencao americana.htm>. Acesso em: 20 mar 2020. 
CORTE INTERAMERICANA DE DIREITOS HUMANOS. Casos contenciosos. Disponível em: $<$ https://www.corteidh.or.cr/cf/Jurisprudencia2/busqueda casos

contenciosos.cfm?lang=es>. Acesso em: 20 mar 2020.

CRESWELL, John W. Investigação qualitativa e projeto de pesquisa: escolhendo entre abordagens. 3aㅡ ed. Porto Alegre: Penso, 2014.

MAZZUOLI, Valério de Oliveira. Direito Internacional: Tratados e Direitos Humanos fundamentais na ordem jurídica brasileira. Rio de Janeiro: América Jurídica, 2001.

PINHEIRO, Carla. Direito Internacional e Direitos Fundamentais. São Paulo: Atlas, 2001.

RAMOS, André de Carvalho. Curso de Direitos Humanos. $7^{\text {a }}$ ed. São Paulo: Saraiva, 2020.

SEVERINO, Antônio Joaquim. Metodologia do Trabalho Científico. 24ạ ed. São Paulo: Cortez, 2016.

SILVA, Lucas Gonçalves; SOUZA, Ana Paula de Jesus. Análise dos casos brasileiros na corte interamericana de direitos humanos: ascensão do transconstitucionalismo? In Revista do Programa de Pós-Graduação em Direito da UFBA, v. 29, n. 01, e-issn 2358-4777, p 98-111, Jan-Jun 2019. Disponível em: file:///Users/herongordilho/Downloads/32526-115629-1SM\%20(2).pdf. Acesso em 29 março 2020. 